\title{
Phenotypic profiles of Armenian grape cultivars
}

\author{
Rouben Aroutiounian ${ }^{1,2,3, a}$, Anna Nebish ${ }^{1,2,3}$, Gagik Melyan ${ }^{3,4}$, and Kristine Margaryan ${ }^{1,2,3}$ \\ ${ }^{1}$ Department of Genetics and Cytology, Yerevan State University, 1 Alex Manoogian, 0025 Yerevan, Armenia \\ ${ }^{2}$ Research Group of Plant Genetics and Immunology, Institute of Molecular Biology of National Academy of Sciences \\ RA, 7 Hasratyan, 0014 Yerevan, Armenia \\ ${ }^{3}$ Armenian Academy of Viticulture and Wine-Making, NGO, 44/36 Tsovakal Isakov, 0004 Yerevan, Armenia \\ ${ }^{4}$ Scientific Center of Viticulture, Fruit-Growing and Wine-Making of the Armenian National Agrarian University, \\ 1139 Merdzavan, Armenia
}

\begin{abstract}
The conservation and sustainable use of grapevine biodiversity in Armenia is particularly important due to the large number of traditional local varieties. Being partially different from European grapevine gene pool, the material of Armenian local cultivars significantly contributes to the understanding of the genetic variation and is valuable source for target selection. During last years many Armenian grapevine cultivars have been already described and their genotypes determined, but some local varieties and wild accessions remain unidentified and their phenotypic characteristics overlooked. The comprehensive analysis of phenotypes is essential for research, including genetic association studies, cultivar evaluation and selection. The goal of our research was the phenotyping on the base of reproductive, carpological and analytical characteristics of 80 Armenian aboriginal and new grape cultivars. Description of phenotypic profiles is important step towards identification and conservation of genetic resources of Armenian grapes. In future, these data can be applied for breeding of improved grape varieties targeted to fresh consumption and wine production.
\end{abstract}

\section{Introduction}

Contrary of its relatively small territory, Armenia shows a wide set of natural conditions. The principal viticultural and winemaking region is the Ararat Valley, around the midstream of the river Araks. There the vines grow mostly at altitudesbetween 850 and $1300 \mathrm{~m}$ a.s.l. The climate is dry and continental due to mountains in most of regions. Armenia combines the diverse types of soil types, from the solonchaks in semi-desert zone to the mountain meadow soils of alpine type. Armenian grape varieties were formed during thousands years of folk selection and later their spectrum was enriched by hybridization. Viticulture is basic field of Armenian agriculture and the production of brandy and wines - one of main branches of its export. In the early 1990s, the central collection of Armenia with 22 ha and 850 varieties was eliminated. Now in three ampelographic collections 140 varieties are preserved, among which 125 are local and 15 are of foreign origin. Of the local ones, 70 are old autochthonous varieties. As results of latest investigation, it became clear that in Armenia there are many forms of wild grapevine Vitis vinifera ssp. sylvestris. Among these, 10 wild forms are planted in the Nalbandyan ampelographic collection.

The conservation and sustainable use of grapevine biodiversity in Armenia is particularly important due to the large number of traditional local varieties. Being partially different from European grapevine gene pool, the material of Armenian local cultivars significantly contributes to the understanding of the genetic variation and is valuable source for target selection.

${ }^{a}$ Corresponding author: rouben_a@hotmail.com
Although the realized research of genotypes and phenotypes of many Armenian grape varieties, some local cultivars and wild accessions remain unidentified and their phenotypic characteristics overlooked.

For the efficient exploitation of genetic resources for breeding new grape cultivars with improved quality and reduced economic and environmental costs, the knowledge of reproductive biology is of high importance, including flower formation, flower sex, ovules and pollen development and sterility - i.e. components of flower development. These traits strongly affect the quantity, size and quality of fruits in many species and particularly in grapevines, especially their impact on grape and wine quality.

For estimation of yield potential the most important estimates of plant development are their biology reproduction and embryogenesis. Female and male sterility are essential factors, negatively effecting on fruit set. Flower bud abscission is the main factor responsible for low yields in grape cultivars [1]. In some cultivars, degenerations occurring during the development of embryo sac or pollen grains lead to the fruitlessness [2]. Although pollination is essential for fruit set, even after an adequate one, only a part of the flowers develop into fruits. Weather conditions and pollution especially at flowering time, as also low temperatures or high humidity can affect ovule development and pollen tube growth [3].

Grape cultivars differ in yield and quantitative and qualitative characteristics of berry. A whole range of phenotyping and genotyping techniques for the identification, characterization, and estimation of the genetic diversity of grapevine resources has been developed over the last few years [4]. The final aim of breeding programs is the production of large berries with desirable characteristics. 
During last years great interest has been paid to plant polyphenols, because these secondary metabolites, naturally presented in fruit and vegetables are part of our everyday diet. As efficient free radical scavengers they can potentially interact with biological systems and play important role in preventing human neurodegenerative diseases, cardiovascular disorders and cancer [5,6]. Phenolics display a diverse variety of structures, ranging from simple moieties containing a single hydroxylated aromatic ring to highly complex polymeric substances. The skins and seeds of grapes are known to be rich sources of phenolic compounds, both flavonoids and non-flavonoids [7,8]. The concentration of phenolic compounds in grapes depends on the variety of grapevine and is influenced by viticultural and environmental factors.

Phenolic compounds are accumulated mostly in berry skins and seeds. For this reason, grape residue extract has become popular in recent years as a nutritional supplement. However, although the literature abounds with reports about phenolic compounds and antiradical activity of grape seeds or skins, there are very few reports comparing distributions of phenolic compounds between seeds and skins among different species and cultivars. Knowledge of the phenolic compound distribution between grape berry seed and skin will contribute to a more comprehensive assessment of the their biological activities. It has been well known that the grape nutritional qualities, determined by genotype, are affected by environmental, cultural, and post-harvesting conditions [9-11]. Knowledge of healthbeneficial nutrition distribution among grape cultivars are very important for improving grape nutritional properties by breeding.

Many Armenian grapevine cultivars have been already described and their genotypes determined. However, Armenian grape germplasm have yet to be fully explored, because many local grapevine accessions remain unidentified and their phenotypic characteristics, including nutritional activities, remain overlooked. At the same time an accurate phenotypic description of varieties needs to be done with combined methodologies which involve the determination of polyphenolic profiles as an important chemical descriptor. Thus, important objective of presented research was to screen Armenian grape cultivars for their phenolic compounds and to better understand their distributions in grape seeds and skins.

The goal of our research was the phenotyping on the base of reproductive, carpological and analytical characteristics of 80 Armenian wine and table aboriginal and new grape cultivars.

\section{Material and methods}

Flowers and berries of grape cultivars traditionally grown in Armenia were obtained from the grapevine germplasm collection of Scientific Center of Viticulture, FruitGrowing and Wine-Making (Merdzavan, Armenia).

\subsection{Preparation of the grape skins and seeds for analyses}

Eighteen coloured and twelve white Armenian grape cultivars were analyzed to determine total polyphenols in skins and seeds extracts. Samples from the cultivars and germplasm accessions were harvested in their technological ripening stage.

The pedicels were removed and the berries were manually skinned. The seeds were separated from the pulp, washed with distilled water and then blotted on paper to remove any residual pulp. The skins and seeds were then extracted in $20 \mathrm{ml}$ of ethanol:water:hydrochloric acid (70:29:1) solution for 24 hours. The extracts were filtered before the total polyphenols spectrophotometric determination.

\subsection{Analysis of total polyphenols}

The Folin-Ciocalteu method was used for the determination of the total polyphenols as suggested by L. Rustioni et al. [12]. In brief, an aliquot $(0.5 \mathrm{ml})$ of the appropriate diluted extracts was added to a $10 \mathrm{~mL}$ volumetric flask, containing $2.5 \mathrm{ml}$ of distilled water. Then, $0.5 \mathrm{ml}$ of Folin-Ciocalteu reagent was added and the contents mixed. After $3-5 \mathrm{~min}, 2 \mathrm{ml}$ of $10 \% \mathrm{Na}_{2} \mathrm{CO}_{3}$ solution was added and made up to a total volume of $10 \mathrm{ml}$ distilled water. After keeping the samples for $90 \mathrm{~min}$ in room temperature their absorbance was read spectrophotometrically at $700 \mathrm{~nm}$ against distilled water as the blank. The total polyphenols were expressed as catechin $\left(\mathrm{mg} \cdot \mathrm{L}^{-1}\right)$ concentration and calculated applying the formula:

$$
\text { Catechin }\left(m g \cdot L^{-1}\right)=186.5 \times \mathrm{E}_{700} \times \mathrm{d}
$$

where $E_{700}=$ absorbance at $700 \mathrm{~nm}, d=$ dilution. Then data were converted in $\mathrm{mg} / \mathrm{kg}$ of grape, based on the berries weights. All samples were prepared in triplicate.

Statistical methods: all data were expressed as mean \pm standard deviation (SD) of three replications for each grape skin and seed extracts tested. The data obtained were analyzed statistically by one-way Analysis of Variance (ANOVA) and Multiple Range Test (STATGRAPHICS Plus).

\subsection{Cytoembryological and morphometric analysis of Armenian grapevines}

Cytoembryological observations were carried out on 25-30 open flowers of investigated cultivars during $30-50 \%$ bloom. Material of 40 Armenian grape cultivars with hermaphroditic flowers was fixed in FAA (37-40\% formaldehyde, glacial acetic acid, 95\% ethanol with concentrations 10\%:5\%:50\%, v/v) at $4^{\circ} \mathrm{C}$, then dehydrated in a graded ethanol series, cleared with xylol and paraffin-embedded at $58^{\circ} \mathrm{C}$ by common cyto-histological techniques [13]. Serial longitudinal and cross-sections of flowers $(8 \mu \mathrm{m}$ thick) were performed with a rotary microtome and stained by Mayer's hematoxylin and eosin solutions (H\&E) [14]. Images were acquired with a Motic M10 digital microscope.

Morphometric features of ripe berries of 15 table and 15 wine Armenian cultivars were described according to the IPGRI, OIV and UPOV phenotypic descriptors (International Plant Genetic Resources Institute, 1997) using ImageJ software. 


\section{Results and discussion}

\subsection{Contents of total polyphenols in Armenian grape skins and seeds}

Skin and seed extracts from thirty different Armenian grape cultivars were analyzed for determination of total polyphenol concentration. The content of total polyphenols expressed as catechin equivalents found in coloured grape cultivars is presented in Table 1.

The total phenolic compounds in grape skin extract varied significantly among the grape cultivars studied. According to the obtained data "Sev Aldara" cultivar presented significantly higher total phenolic content (2033.18 mg/kg of grape) when compared to the other accessions, followed by "Karmrahyut", "Avagi 2" and "Tozot" cultivars. However, significant differences in skin total phenolic content were not found among "Vardabuyr" and "Hadisi" or among "Sev Khardji" and "Movsesi Aghavnadzori" cultivars $(p>0.05)$. The highest total phenolic content in seed extract was recorded in "Karmrahyut" cultivar (1970.84 mg/kg of grape), followed by "Sev Aldara" and "Armenia" cultivars $(p<0.05)$. Significantly lower seed total phenolic content was found in "Seyrak Areni" cultivar $154.53 \mathrm{mg} / \mathrm{kg}$ of grape $(p<0.05)$.

The content of total phenols found in white grape cultivars is presented in Table 2. Analysis of white grape cultivars revealed that in "Muscat tuyl" (1497.83 mg/kg

Table 1. Content of total phenols in Armenian coloured grape cultivars.

\begin{tabular}{lll}
\hline $\begin{array}{c}\text { Colored grape } \\
\text { cultivars }\end{array}$ & $\begin{array}{c}\text { Skin polyphenol } \\
\text { content } \\
\text { (mg/kg of grape) }\end{array}$ & $\begin{array}{c}\text { Seed polyphenol } \\
\text { content } \\
(\mathbf{m g} / \mathbf{k g} \text { of grape })\end{array}$ \\
\hline Sev Aldara & $2033.18 \pm 37.20^{\mathrm{k}}$ & $1430.69 \pm 194.44^{\mathrm{g}}$ \\
\hline Karmrahyut & $1172.46 \pm 6.69^{\mathrm{gh}}$ & $1970.84 \pm 69.40^{\mathrm{h}}$ \\
\hline Avagi 2 & $1513.07 \pm 207.17^{\mathrm{j}}$ & $656.17 \pm 131.96^{\mathrm{def}}$ \\
\hline Tozot & $1434.73 \pm 24.28^{\mathrm{ij}}$ & $555.45 \pm 74.33^{\mathrm{cde}}$ \\
\hline Sev Khardji & $1008.18 \pm 122.10^{\mathrm{defg}}$ & $760.08 \pm 358.25^{\mathrm{ef}}$ \\
\hline Vardabuyr & $869.90 \pm 184.40^{\mathrm{bcd}}$ & $832.40 \pm 107.70^{\mathrm{f}}$ \\
\hline Sev Sateni & $920.40 \pm 106.70^{\mathrm{cde}}$ & $736.70 \pm 55.01^{\mathrm{ef}}$ \\
\hline Armenia & $710.30 \pm 101.90^{\mathrm{b}}$ & $842.04 \pm 166.80^{\mathrm{f}}$ \\
\hline Movsesi clone & $1108.10 \pm 141.10^{\mathrm{efgh}}$ & $404.10 \pm 67.70^{\mathrm{bc}}$ \\
\hline B & $1249.12 \pm 112.65^{\mathrm{hi}}$ & $230.62 \pm 21.79^{\mathrm{ab}}$ \\
\hline X1 & $794.80 \pm 44.90^{\mathrm{hij}}$ & $415.95 \pm 28.70^{\mathrm{a}}$ \\
\hline E & $956.53 \pm 146.15^{\mathrm{cdef}}$ & $458.36 \pm 96.0^{\mathrm{cd}}$ \\
\hline Movsesi & $1164.02 \pm 110.06^{\mathrm{fgh}}$ & $203.23 \pm 68.75^{\mathrm{ab}}$ \\
\hline Hadisi & $876.06 \pm 15.19^{\mathrm{bcd}}$ & $381.53 \pm 53.21^{\mathrm{bc}}$ \\
\hline $\begin{array}{l}\text { Movsesi } \\
\text { Aghavnadzori }\end{array}$ & $1008.90 \pm 207.40^{\mathrm{defg}}$ & $226.20 \pm 36.90^{\mathrm{ab}}$ \\
\hline Lyustra & $671.8 \pm 117.60^{\mathrm{ab}}$ & $558.40 \pm 63.30^{\mathrm{cde}}$ \\
\hline Seyrak Areni & $968.90 \pm 103.03^{\mathrm{bc}}$ & $154.53 \pm 26.27^{\mathrm{a}}$ \\
\hline Nalbandyan & $482.10 \pm 91.0^{\mathrm{a}}$ & $559.42 \pm 94.30^{\mathrm{cde}}$ \\
\hline $\begin{array}{l}\text { Average value } \pm \text { standard deviation }(n=3), \text { number }^{\mathrm{c}} \text { with no letters in common is } \\
\text { significantly different }(p<0.05) .\end{array}$ & \\
\hline
\end{tabular}

of grape), "V 1" (1335.18 mg/kg of grape) and "Nazeli" $(1289.10 \mathrm{mg} / \mathrm{kg}$ of grape) skin extracts demonstrated significantly higher total phenolic content $(p<0.05)$ with respect to the other accessions. However, significant differences in skin total phenolic content were not found among "Ayvazyani muscateni” and "99/1 Derei”, or among "Tokun" and "Khach khardji" cultivars $(p>0.05)$. A significantly higher total phenolic content in seed extract was found in "Ampaguyn" cultivar $(609.57 \mathrm{mg} / \mathrm{kg}$ of grape) with respect to the other white grape varieties $(p<0.05)$. Significant differences in seed total phenolic content were not found among "Muscat tuyl" and "Parvana" or among "Muscat Erevani", "Tokun" and "Khach khardji" cultivars $(p>0.05)$.

On the base of obtained results revealed that "Sev Aldara" (3463.88 mg/kg of grape), "Karmrahyut" (3143.31 mg/kg of grape) and "Avagi 2" (2169.25 mg/ $\mathrm{kg}$ of grape) cultivars with black skin have the highest total phenolic content. Among white grapes high level of total phenolic content was determined for "Muscat tuyl" (1640.43 mg/kg of grape), "V 1" (1620.01 mg/kg of grape) and "Ampaguyn" (1587.94 mg/kg of grape) cultivars.

Genetic, agronomic or environmental factors have important roles in berry phenolic composition and concentration. It is well known that the composition of phenols in grapevines depends from variety, species, season, environmental and management factors such as soil conditions, climate and crop load. The total phenols content of red grape skins is higher than that of white grapes probably due to the loss of the ability to produce anthocyanins in the skins of white grapes. Our results indicate that the phenolic content of berries and distribution of these compounds in skins and seeds depends mainly on the grape skin color and variety.

Table 2. Content of total phenols in Armenian white grape cultivars.

\begin{tabular}{lll}
\hline $\begin{array}{c}\text { White grape } \\
\text { cultivars }\end{array}$ & $\begin{array}{c}\text { Skin polyphenolic } \\
\text { content } \\
\text { (mg/kg of grape) }\end{array}$ & $\begin{array}{c}\text { Seed polyphenolic } \\
\text { content } \\
\text { (mg/kg of grape) }\end{array}$ \\
\hline Muscat tuyl & $1497.83 \pm 451.37^{\mathrm{g}}$ & $142.56 \pm 20.36^{\mathrm{b}}$ \\
\hline V1 & $1335,18 \pm 149.22^{\mathrm{fg}}$ & $284.83 \pm 19.05^{\mathrm{d}}$ \\
\hline $\begin{array}{l}\text { Ampaguyn } \\
\text { (Mor-mor) }\end{array}$ & $978.40 \pm 10.80^{\mathrm{de}}$ & $609.57 \pm 65.22^{\mathrm{g}}$ \\
\hline Nazeli & $1289.10 \pm 13.80^{\mathrm{fg}}$ & without seeds \\
\hline Nazeli clone & $1158.50 \pm 98.0^{\mathrm{ef}}$ & without seeds \\
\hline $\begin{array}{l}\text { Muscat } \\
\text { Yerevani }\end{array}$ & $256.30 \pm 65.50^{\mathrm{a}}$ & $222.60 \pm 28.18^{\mathrm{c}}$ \\
\hline $\begin{array}{l}\text { Ayvazyani } \\
\text { muscateni }\end{array}$ & $696.22 \pm 82.96^{\mathrm{c}}$ & $362.09 \pm 41.58^{\mathrm{e}}$ \\
\hline Mskhali & $527.50 \pm 17.20^{\mathrm{bc}}$ & $523.18 \pm 40.97^{\mathrm{f}}$ \\
\hline 99/1 Derei & $651.23 \pm 18.78^{\mathrm{c}}$ & $385.77 \pm 30.78^{\mathrm{e}}$ \\
\hline Parvana & $304.80 \pm 34.40^{\mathrm{ab}}$ & $136.95 \pm 33.35^{\mathrm{b}}$ \\
\hline Tokun & $744.40 \pm 49.20^{\mathrm{cd}}$ & $199.21 \pm 21.47^{\mathrm{c}}$ \\
\hline Khach khardji & $740.03 \pm 91.50^{\mathrm{cd}}$ & $202.23 \pm 7.18^{\mathrm{c}}$ \\
\hline Average value \pm standard deviation $(n=3)$, number with no letters in common is
\end{tabular}

significantly different $(p<0.05)$. 

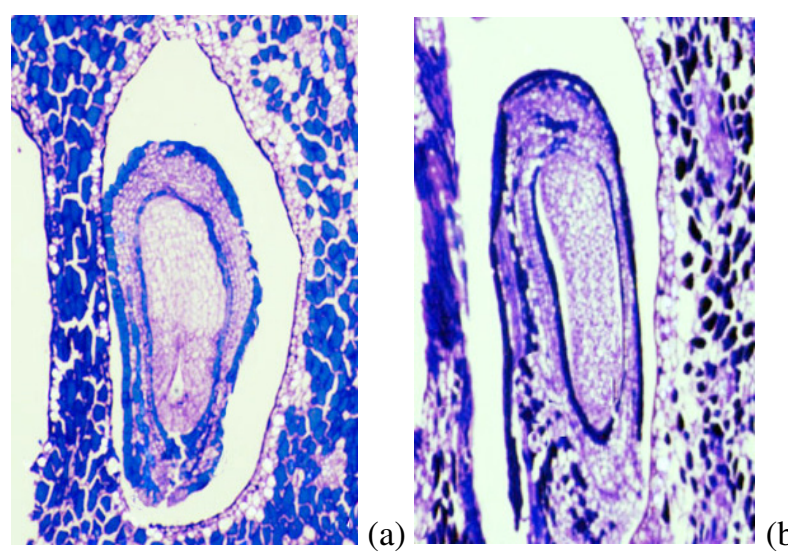

Figure 1. (a) Normal developed ovule with egg cell and contours of synergids in the embryo sac. (b) Degenerated ovule without cells of embryo sac, characterized by wrinkled inner integument, separated from the outer one.

The conservation of grapevine biodiversity in Armenia is particularly important because of the large number of traditional local varieties out of cultivation. These resources could be relevant for the selection of new cultivars. The presented work is a first step towards identification and conservation of genetic resources of Armenian grapes.

\subsection{Cytoembryological analysis of investigated cultivars}

In reproductive biology of grapes the key role plays the development of inflorescences and flowers, and especially ovule formation with 8 cells in the embryo sac.

Cytoembryological study revealed abnormalities during either different stages of the meiosis of megaspore mother cell or process of gametogenesis and embryo sac formation. Thus ovule development was arrested and appeared the beginning of the degeneration processes (Fig. 1a and 1b).

For seeded cultivars the number of developed ovules per flower varied from 0.9 ("Mskhali", "Ararati") to 2.8 ("Erebuni", "Muscat Yerevanyan", "Shahumyani") in average (instead of formation of potential 4 ovules). The exception was revealed for Voskehat cultivar which produce 4-5 ovules per flower (Fig. 2).

After fertilization some degree of embryo growth is required for the fruit formation. In our experiments not all developed ovules formed seeds with both embryo and endosperm. Post-fertilization embryo or endosperm abortions, called stenospermocarpy, is very widespread in Armenian cultivars. The percentage of developed seeds after fertilization of formatted ovules in investigated cultivars varied from 55.2-59.6\% ("Voskehat", "Hayreniq", "Mskhali", "Muscat Yerevanyan") to 95.8-99.4\% ("Kakhet", "Sev Aldara", "Tozot"). The lowest number of seeds was registered in "Mskhali" and "Ararati" (approximately 0.5 developed seed per berry in average). The highest level of abnormalities was detected in stenospermocarpic cultivars "Anahit", "Alvard" and "Parvana", that produced berries containing up to 0.8 small undeveloped seeds per berry in average. However, no significant differences have been found between ovule and seed number between wine and table grapes.

\subsection{Morphometric carpological analysis}

Morphometric analysis revealed the wide range of berries by sizes, weight, color and shapes. The average berry weight varies from 1.2 to $1.3 \mathrm{~g}$ for "Azateni", "Burmunq", "Muscat haykakan" and "Karmrahyut" wine cultivars to 5.6 g "Armenia", "Erebuni", "Ararati" and "Hayrenik" table cultivars, the heaviest berries are registered for Shahumyani $-6.40 \pm 0.12$ g. Berry length ranges from 12.7

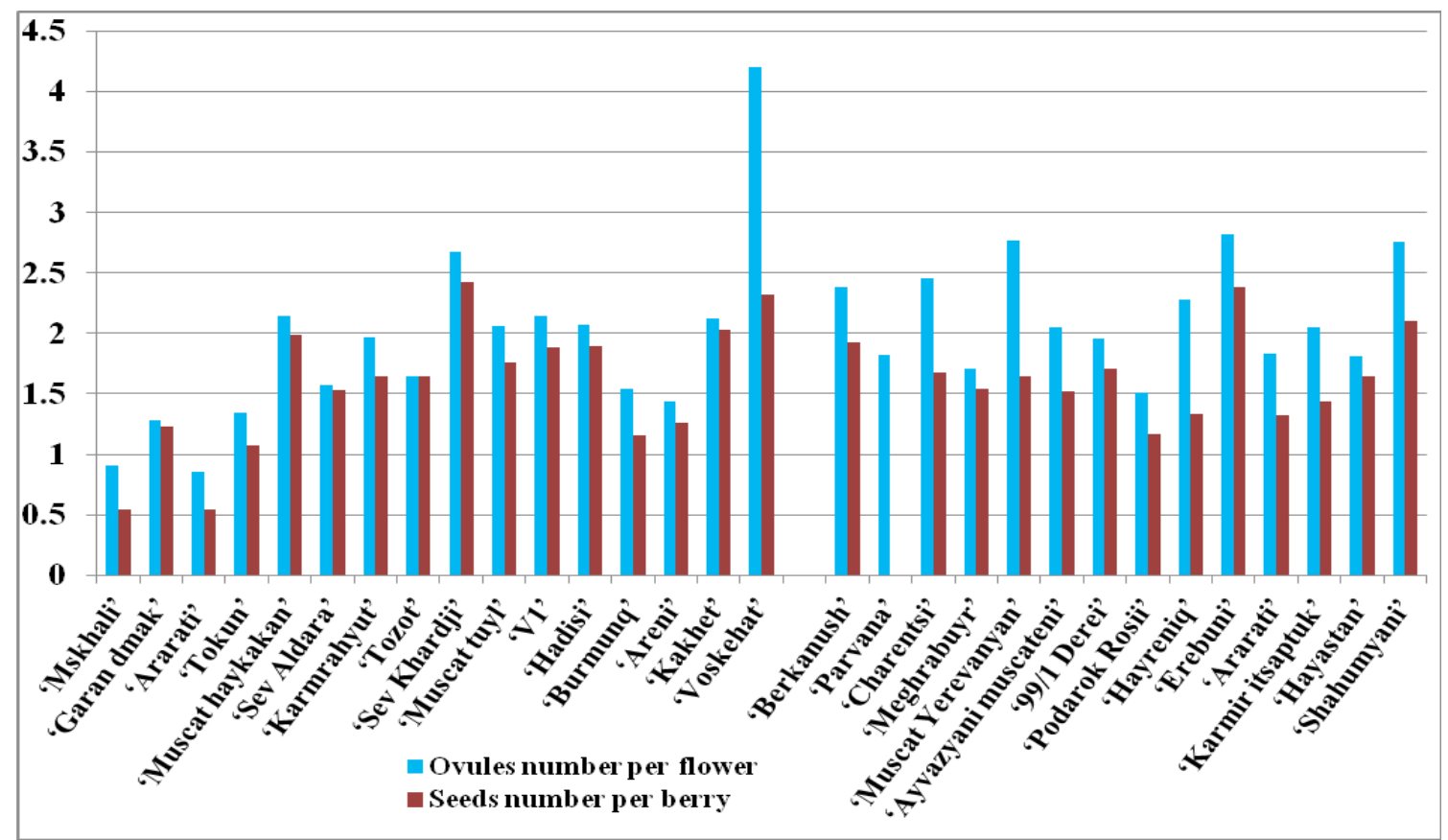

Figure 2. Developed ovules number per flower and seeds number per berry of some Armenian grapevine cultivars. 
to $14.6 \mathrm{~mm}$ ("Karmrahyut", "Berkanush", "Muscat haykakan") to $31.2 \mathrm{~mm}$ ("Shahumyani", "99/1 Derei") in average. Berry width ranges from 12.4-13.0 mm ("Karmrahyut", "Berkanush") to 24.0-24.5 mm ("Erebuni", "Hayreniq", "Hayastan"). Morphometric study of the investigated accessions demonstrated that table cultivars formed significantly heavier and larger berries than wine cultivars $(p<0.05)$.

The presented results suggest wide polymorphism for traditionally grown investigated Armenian grapevine cultivars by both cytoembryological and morphometric features. Table and wine cultivars are characterized with different levels of abnormalities during ovule development and seed formation. Data of morphometric carpological characteristics of investigated cultivars will be included in the Armenian grape varieties database and can be used as markers for parental selection in breeding programs.

\section{Conclusions}

Description of phenotypic profiles is important step towards identification and conservation of genetic resources of Armenian grapes. Results reported here can be used for Armenian grapevine phenotyping as important cytoembryological, morphometric and chemical descriptors. The comprehensive analysis of phenotypes is essential for selection and research applications, including genetic association studies and cultivar evaluation. In the next future, these data can also find application for selection of improved grape varieties targeted to fresh consumption and wine production.

We are grateful for productive participation in the COST Action FA1003 "East-West Collaboration for Grapevine Diversity Exploration and Mobilization of Adaptive Traits for Breeding" that was realized by establishing preliminary database for the Armenian grape phenotyping.

\section{References}

[1] D.I. Jackson, Am. J. Enol. Vitic. 42, 290-294 (1991)

[2] A. Ebadi, P. May, M. Sedgley, B.G. Coombe, Aust. J. Grape Wine Res. 1, 11-18 (1995)

[3] G. Lebon, E. Duchene, O. Brun, C. Clement, Ann. Bot. 95, 943-948 (2005)

[4] L. Fernandez, L. Torregrosa, N. Terrier, L. Sreekantan, J. Grimplet, C. Davies, M.R. Thomas, C. Romieu, A. Ageorges, J. Plant Mol. Biol., 63, 307-323 (2007)

[5] J.B. German, E.N. Frankel, A.L. Waterhouse, R.J. Hansen, R.L. Walmez, In T.R. Watkins (Ed.), Wine nutritional and therapeutic benefits, 196-214, (Washington, DC: American Chemical Society,1997)

[6] P. R. Poudel, H. Tamura, I. Kataoka, R. Mochioka, Journal of Food Composition and Analysis, 21, 622-625, (2008)

[7] A. Arnous, A. S. Meyer, Food and Bioproducts Processing, 86(7), 9-86 (2008)

[8] M. Pinelo, A. Arnous, A. S. Meyer, Trends in Food Science and Technology, 17, 579-590 (2006).

[9] A.M. Connor, J.J. Luby, C.B.S. Tong, C.E. Finn, J.F. Hancock, Journal of the American Society for Horticultural Science, 1, 82-88 (2002)

[10] R.L. Prior, G. Cao, A. Martin, J. Sofic McEwen, C. O'Brien, Journal of Agricultural and Food Chemistry, 46, 2686-2693 (1998)

[11] A.R. Proteggente, A.S. Pannala, G. Pagana, L. Van Buren, E. Wagner, S. Wiswman, et al., Free Radical Research, 36, 217-233 (2002)

[12] L. Rustioni, D. Maghradze, C.F. Popescu, G. Cola, E. Abashidze, R. Aroutiounian et al., Vitis. 53(4), 219-226 (2014)

[13] S.E. Ruzin, Plant microtechniques and microscopy, Oxford University Press, 336 (1999)

[14] J.D. Bancroft, M. Gamble, Theory and Practice of Histological Techniques. Elsevier Health Sciences, 744 (2007) 